\title{
Diabetes prevalence and metabolic risk profile in an unselected population visiting pharmacies in Switzerland
}

\author{
Alexandre Rey' \\ Martin Thoenes ${ }^{1,2}$ \\ Rolf Fimmers ${ }^{3}$ \\ Christoph A Meier ${ }^{4}$ \\ Peter Bramlage ${ }^{5}$
}

'Sanofi Aventis, Medical Department, Meyrin, Switzerland; ' Institute for Clinical Pharmacology, Medical

Faculty Carl Gustav Carus, Technical University Dresden, Germany; ${ }^{3}$ Institut für Medizinische Biometrie, Informatik und Epidemiologie, Universität Bonn, Germany; ${ }^{4}$ Klinik für Innere Medizin, Stadtspital Triemli, Zürich, Switzerland; ${ }^{5}$ Institut für Pharmakologie und präventive Medizin, Mahlow, Germany

Correspondence: Peter Bramlage Institut für Pharmakologie und präventive Medizin, Menzelstrasse 21, I583| Mahlow, Germany

Tel +4933793147890

Fax +4933793।47892

Email peter.bramlage@ippmed.de
This article was published in the following Dove Press journal:

Vascular Health and Risk Management

20 September 2012

Number of times this article has been viewed

Background: Diabetes represents one of the major health challenges in Switzerland, and early diagnosis and treatment is mandatory to prevent or delay diabetes-related morbidity and mortality. For the purpose of identifying affected individuals, early screening in pharmacies is a valuable option. In this survey, we aimed to determine blood glucose and metabolic control in an unselected population of individuals visiting Swiss pharmacies.

Methods: The subjects responded to a short questionnaire and underwent a single capillary blood glucose test for screening purposes. They were classified as normal, indeterminate, impaired fasting glucose, and diabetes according to predefined blood glucose levels.

Results: A total of 3135 individuals (mean age 56 years) in 18 cantons were screened in November 2010; of these, 4.2\% (95\% confidence interval [CI] 3.5-4.9) had previously been diagnosed with diabetes. Diabetes was newly diagnosed in 1.9\% (95\% CI 1.5-2.4), and 11.5\% (95\% CI 10.4-12.6) had impaired fasting glucose. Subjects with impaired glucose control had an increased body mass index, a frequent family history of diabetes, hypertension, hypercholesterolemia, smoking, and a low level of physical activity. Prevalence of impaired glucose control was different between the French/Italian-speaking part of Switzerland (new diabetes 4.9\%; impaired fasting glucose $12.7 \%$ ) and the German-speaking part (new diabetes 1.9\%; impaired fasting glucose $10.3 \%$ ).

Conclusion: Our study shows a $6.1 \%$ prevalence of diabetes, of which about a third $(1.9 \%)$ was previously undiagnosed, and $11.5 \%$ had impaired fasting glucose. Therefore, screening initiatives in pharmacies may be suitable for detecting people with undiagnosed diabetes.

Keywords: diabetes, pharmacy, epidemiology, screening

\section{Introduction}

There is an increasing prevalence of type 2 diabetes globally, which is attributable to a growing global population, an increase in life expectancy, increased diagnostic efforts, and a reduced diabetes risk attributable to recent advances in diabetes treatment. ${ }^{1}$ Therefore, diabetes is a major driver of health care costs. ${ }^{2}$

For Switzerland, a diabetes prevalence of 3.3\% has been reported for 1997 and an increase to $4.8 \%$ in the year $2007 .{ }^{3}$ Other data from a large population-based study conducted in the French part of Switzerland point to an even higher prevalence. ${ }^{4}$ Therefore, it is not surprising that type 2 diabetes and its complications contribute to $2.2 \%$ of Switzerland's health care expenditure. ${ }^{5}$

Early diagnosis and treatment is mandatory to prevent or delay diabetes-related morbidity and mortality and reduce health care costs. Within this context, measurement of blood glucose levels during screening initiatives may help to identify persons 
with unknown diabetes or impaired fasting glucose and to initiate preventative measures or appropriate therapy in a timely manner. Pharmacies are particularly suitable for this purpose, because they are an easily accessible point of contact for individuals not visiting physicians.

Based on these considerations, we conducted a national survey in pharmacies of the AMAVITA chain documenting more than 3000 individuals with respect to their random blood glucose values and further cardiometabolic parameters. Our aim was to assess glucose values, classify observed values into normal, indeterminate, impaired fasting glucose, and definite diabetes, in a largely unselected population of pharmacy attendees.

\section{Materials and methods}

Individuals visiting a participating pharmacy in one of 18 cantons of Switzerland were enrolled into the present study. Participants were selected based on their willingness to undergo blood glucose testing and to provide information on their cardiometabolic risk profile, without any further predefined selection criteria. Patients not willing to participate were neither documented nor counted to determine participation rates.

Prior to enrollment, all study participants received a written information leaflet explaining the survey objectives and procedures. The study was conducted in accordance with applicable Swiss national regulations for epidemiologic studies and good epidemiologic practice, and informed verbal consent was obtained. A signed informed consent form was not required, because no personal data were registered and measurement of blood glucose is a standard procedure in Swiss pharmacies.

\section{Documentation}

On an anonymized one-page case report form, participants were asked to report the time of their last meal, as well as their gender, age, body weight, and height. The following parameters were also documented: presence or absence of diabetes, antidiabetic treatment, family history of diabetes or, in women, a weight of more than $4 \mathrm{~kg}$ of their newborns, a history of cardiovascular events (myocardial infarction, stroke), and cardiovascular risk factors (hypertension, hypercholesterolemia, smoking, physical exercise). Physical exercise was classified as no activity, moderate (at least 30 minutes/day for 5 days/week, eg, walking, dancing, gardening), or strenuous (at least 20 minutes/day on 3 days a week, eg, jogging, swimming, team sports).

\section{Blood glucose classification}

Capillary blood glucose was measured in all study participants using a uniform blood glucose monitoring device (Accu-Check ${ }^{\circledR}$ Aviva, Roche, Basel, Switzerland) according to the manufacturer's instructions. Based on their blood glucose values, study participants were categorized as either fasting (last meal $\geq 8$ hours), or nonfasting (last meal $<8$ hours), and were further subclassified into four different groups based on their blood glucose levels as follows: normal blood glucose $(<5.6 \mathrm{mmol} / \mathrm{L}$ for fasting/nonfasting), diabetes status indeterminate $(5.6$ to $<11.1 \mathrm{mmol} / \mathrm{L}$ for nonfasting), impaired fasting glucose $(5.6-6.9 \mathrm{mmol} / \mathrm{L}$ for fasting), and diabetes $(\geq 7 \mathrm{mmol} / \mathrm{L}$ for fasting; $\geq 11.1 \mathrm{mmol} / \mathrm{L}$ for nonfasting).

\section{Regional analyses}

For the regional analyses, cantons were subdivided into the German-speaking population (SUI-GER) which comprised the cantons Aargau, Bern, Basel-Land, Basel-Stadt, Graubünden, Luzern, St Gallen, Solothurn, Zug, and Zurich, and the French/ Italian speaking population (SUI-FR/IT) comprising Fribourg, Geneva, Jura, Neuchâtel, Tessin, Waadtland, and Wallis.

\section{Statistical analysis}

We performed a descriptive analysis of the data. For this purpose, only participants with complete data regarding the individual parameters were considered. Continuous variables are shown as the mean \pm standard deviation, and categorical variables as percentages. $P$ values for comparison between groups of patients were calculated using the two-sided $t$-test for quantitative variables and the $\chi^{2}$ test for qualitative variables.

\section{Results}

A total of 3135 participants were enrolled by 102 pharmacies in November 2010. The study population comprised $27 \%$ males, had a mean age of 56 years and a mean body mass index of $25 \mathrm{~kg} / \mathrm{m}^{2}$. Mean random blood glucose was $6.0 \pm 1.5 \mathrm{mmol} / \mathrm{L}$, and about one quarter (23.0\%) of participants were in a fasting state (Table 1). The presence of diabetes was self-reported by $131 / 3135$ participants $(4.2 \%$; $95 \%$ confidence interval [CI] 3.5-4.9), and the majority of these known diabetic participants $(67.2 \%)$ were treated with oral antidiabetic drugs alone. A total of $6.1 \%$ received an insulin-containing regimen (insulin alone or basal insulinassisted oral antidiabetic treatment) and $24.4 \%$ received diet and exercise alone. 
Table I Participant characteristics (total $\mathrm{n}=3135$ )

\begin{tabular}{|c|c|c|c|c|c|}
\hline & $\begin{array}{l}\text { Variable } \\
\text { available* }\end{array}$ & $\begin{array}{l}\text { Total** } \\
\% / \text { mean } \pm \text { SD }\end{array}$ & $\begin{array}{l}\text { SUI-GER *** } \\
\% / \text { mean } \pm \text { SD }\end{array}$ & $\begin{array}{l}\text { SUI-FR/IT*** } \\
\% / \text { mean } \pm \text { SD }\end{array}$ & $\begin{array}{l}P \text { value for } G E R \\
\text { versus } F R / I T\end{array}$ \\
\hline Total (n) & 3135 & & $168 \mid$ & 1454 & \\
\hline Male & 2935 & 26.5 & 27.1 & 25.8 & 0.429 \\
\hline Age (years) & 3047 & $56.1 \pm 16.6$ & $57.5 \pm 16.5$ & $54.6 \pm 16.4$ & $<0.001$ \\
\hline Body weight $(\mathrm{kg})$ & 2997 & $69.4 \pm 14.2$ & $69.7 \pm 14.1$ & $69.1 \pm 14.3$ & 0.249 \\
\hline Body mass index $\left(\mathrm{kg} / \mathrm{m}^{2}\right)$ & 2983 & $24.9 \pm 4.3$ & $24.9 \pm 4.2$ & $24.9 \pm 4.3$ & 0.417 \\
\hline Blood glucose (mmol/L) & 2989 & $6.0 \pm 1.5$ & $6.0 \pm 1.5$ & $6.0 \pm 1.5$ & 0.221 \\
\hline Fasting state & 3120 & 23.0 & 19.1 & 27.6 & $<0.001$ \\
\hline Known diabetes & 3091 & 4.2 & 3.6 & 5.0 & 0.063 \\
\hline OAD & $|3|$ & 67.2 & 55.0 & 77.5 & \\
\hline BOT & $|3|$ & 2.3 & 3.3 & 1.4 & \\
\hline Insulin & $|3|$ & 6.1 & 10.0 & 2.8 & \\
\hline No drugs & $|3|$ & 24.4 & 31.7 & 18.3 & \\
\hline \multicolumn{6}{|l|}{ Family history of diabetes } \\
\hline Father & 3058 & 9.0 & 8.1 & 10.1 & 0.054 \\
\hline Mother & 3077 & 13.6 & 13.0 & 14.2 & 0.363 \\
\hline High birthweight (women) & 2824 & 7.3 & 8.0 & 6.5 & 0.136 \\
\hline Hypertension & 3090 & 25.0 & 24.1 & 26.0 & 0.205 \\
\hline Blood pressure (mmHg) & 412 & & & & \\
\hline Systolic & 410 & $138.1 \pm 15.1$ & $139.5 \pm 13.9$ & $137.0 \pm 16.0$ & 0.046 \\
\hline Diastolic & 409 & $82.5 \pm 10.6$ & $82.1 \pm 9.9$ & $82.9 \pm 11.2$ & 0.091 \\
\hline Hypercholesterolemia & 2951 & 16.0 & 14.8 & 17.3 & 0.067 \\
\hline Smoking & 3124 & 17.7 & 15.7 & 20.0 & 0.002 \\
\hline Physical exercise & 3003 & & & & \\
\hline No/minimal & 614 & 21.8 & 13.6 & 31.1 & $<0.001$ \\
\hline Moderate & 1750 & 58.3 & 62.8 & 53.2 & \\
\hline Strenuous & 599 & 19.9 & 23.6 & 15.8 & \\
\hline History of myocardial infarction & 3116 & 2.3 & 2.4 & 2.3 & 0.977 \\
\hline History of stroke & 3095 & 1.5 & 1.2 & 1.9 & 0.129 \\
\hline
\end{tabular}

Notes: *Variable available together with regional (canton) information; **variable available; ***variable available and belonging to the region.

Abbreviations: SD, standard deviation; OAD, oral antidiabetic drug; BOT, basal insulin assisted oral antidiabetic treatment; SUI-FR/IT, French/Italian-speaking part of Switzerland; SUI-GER, German speaking part of Switzerland.

\section{Prevalence of unknown impaired glucose control}

Of 3004 participants with previously unknown diabetes, $86.7 \%$ had a normal $(43.2 \%)$ or indeterminate $(43.5 \%)$ blood glucose status, $11.5 \%$ were diagnosed with impaired fasting glucose, and $2.0 \%$ had new diabetes. Impaired glucose control was particularly prevalent in older age $(P<0.001)$, male patients $(P=0.011)$, and those with a body mass index $>25 \mathrm{~kg} / \mathrm{m}^{2}(P<0.001)$. The prevalence was also higher in participants with risk factors, such as hypertension, hypercholesterolemia, and smoking $(P<0.001$, Table 2$)$.

\section{SUI-GER versus SUI-FR/IT}

In the total cohort, the diabetes prevalence was $6.1 \%$ (CI 5.3-7.0, Figure 1). A total of 1681 participants were from the SUI-GER region, and 1454 participants from the SUI-FR/ IT region (Table 3). Mean blood glucose levels were similar in both regions of Switzerland. In the SUI-FR/IT region, the participants were younger $(P<0.001)$ and were more often fasting $(P<0.001)$, while the prevalence of diabetes was only nominally higher and many participants were treated with oral antidiabetic drugs compared with SUIGER. Furthermore, participants in SUI-FR/IT had lower blood pressure values $(P=0.046)$, were more likely to be smokers $(P=0.002)$, and had a low level of physical activity $(P<0.001$, Table 1$)$.

The regional comparison (Table 3 ) showed a lower number of participants with known diabetes in the SUI-FR/IT region $(5.0 \%$ versus $3.6 \%$ in SUI-GER; $P=0.063$ ), whereas no regional difference was seen with regard to newly diagnosed diabetes ( $1.9 \%$ for both).

The frequency of a normal glucose profile varied between $30.7 \%$ (Basel-Stadt) and 52.8\% (Tessin), whereas impaired fasting glucose was most frequently diagnosed in Geneva $(17.2 \%)$, but in only $5 \%$ of participants in the canton of Jura. The presence of diabetes was most frequently reported 


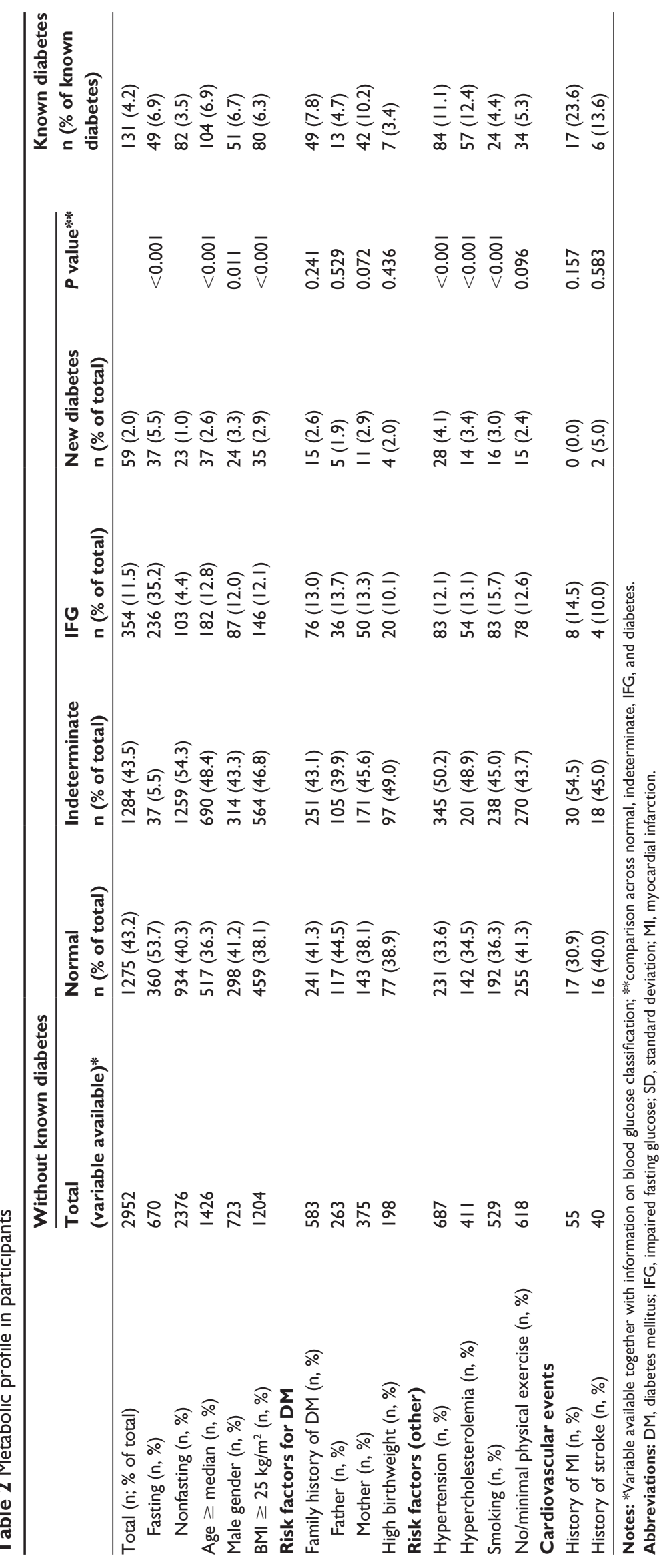




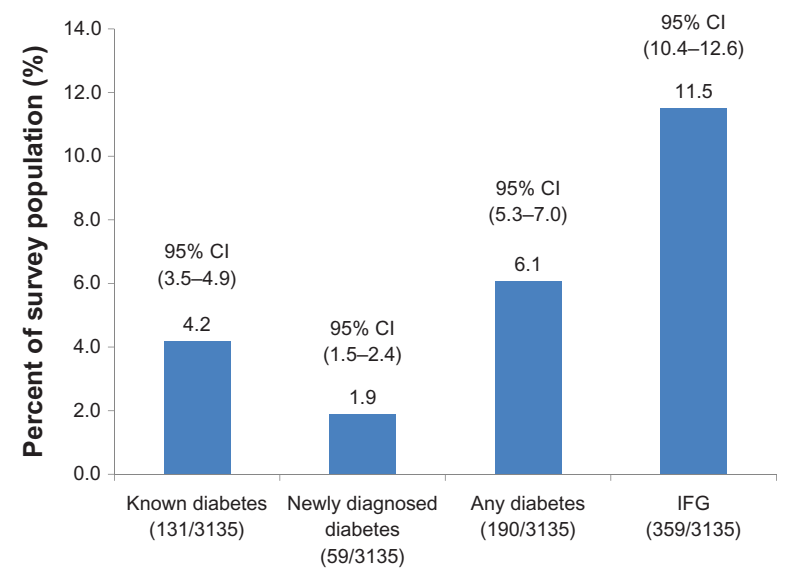

Figure I Prevalence of diabetes.

Abbreviations: $\mathrm{Cl}$, confidence interval; IFG, impaired fasting glucose.

in Geneva (8.0\%) and least frequently in the canton of Jura (1\%). Most cases of new diabetes were detected in the canton of Zug (6.0\%), whereas the lowest number of new diabetes cases was seen in the canton of Graubünden $(0.5 \%)$ and Wallis (1\%). Due to low numbers of study participants, the cantons of Schaffhausen, Solothurn, and Waadtland were not considered for this comparison.

\section{Discussion}

Our analysis shows a $6.1 \%$ prevalence of diabetes in an unselected Swiss population visiting a pharmacy and agreeing to participate in our survey, of which $4.2 \%$ had known diabetes and $1.9 \%$ were newly detected by capillary blood glucose determination. These data not only confirm a recently published prevalence of $4.8 \%$ in a population aged 18 to $>65$ years (nationwide, population-based telephone survey), but indicate stable prevalence of diabetes from 2007 to 2010 using a similar methodologic approach. ${ }^{3}$ However, based on the number of newly diagnosed diabetic participants in our survey, it can be assumed that the real diabetes burden in Switzerland is higher than previously reported.

\section{Diabetes prevalence in perspective}

According to the International Diabetes Federation, an estimated 629,000 participants (aged 20-79 years) in Switzerland suffer from diabetes, corresponding to a prevalence of $8.9 \%$. These numbers are similar to those in Germany and Austria, but higher than in other northern European countries, such as Belgium, The Netherlands (5.3\%), and France (6.7\%). However, accurate prevalences of diabetes can only be derived from structured, population-based studies. From a methodologic perspective, our investigation does not fullfill all the criteria of a proper population-based study and the willingness to undergo voluntary blood glucose testing might favor the enrollment of the more health-conscious subjects. Nevertheless, participants consulting a pharmacist can be considered as a largely unselected population due to the large

Table 3 Distribution of glucose control by region and canton based on a total survey population of 3135

\begin{tabular}{|c|c|c|c|c|c|}
\hline Region/canton & $\begin{array}{l}\text { Inhabitants } \\
(\times 1000)\end{array}$ & $\begin{array}{l}\text { Number } \\
\text { of participants }\end{array}$ & $\begin{array}{l}\text { IFG } \\
\text { n (\% of participants) }\end{array}$ & $\begin{array}{l}\text { Newly diagnosed diabetes } \\
\text { n (\% of participants) }\end{array}$ & $\begin{array}{l}\text { Known diabetes } \\
\text { n (\% of participants) }\end{array}$ \\
\hline SUI-GER & 4688 & $168 \mid$ & $174(10.4)$ & $32(1.9)$ & $60(3.6)$ \\
\hline Aargau & 600 & 143 & $8(5.6)$ & $5(3.5)$ & $4(2.8)$ \\
\hline Bern & 974 & 403 & $36(8.9)$ & $8(2.0)$ & $12(3.0)$ \\
\hline Basel-Land & 173 & 38 & $3(7.9)$ & $0(0)$ & $2(5.3)$ \\
\hline Basel-Stadt & 188 & 300 & $45(15.0)$ & $6(2.0)$ & $9(3.0)$ \\
\hline Graubünden & 192 & 203 & II (5.4) & $\mathrm{I}(0.5)$ & $6(3.0)$ \\
\hline Luzern & 372 & 91 & $7(7.7)$ & $2(2.2)$ & $9(9.9)$ \\
\hline St Gallen & 474 & 150 & $14(9.3)$ & $2(1.3)$ & $2(1.3)$ \\
\hline Solothurn & 253 & 16 & $3(18.7)$ & $0(0)$ & $0(0.0)$ \\
\hline Zug & 111 & 50 & $4(8.0)$ & $3(6.0)$ & I $(2.0)$ \\
\hline Zurich & $135 \mid$ & 283 & $41(14.5)$ & $5(1.8)$ & $15(5.3)$ \\
\hline SUI-FR/IT & 2482 & 1454 & $185(12.7)$ & $27(1.9)$ & $71(4.9)$ \\
\hline Fribourg & 273 & 299 & $28(9.4)$ & $5(1.7)$ & $9(3.0)$ \\
\hline Geneva & 453 & 425 & $73(17.2)$ & $7(1.6)$ & $34(8.0)$ \\
\hline Jura & 70 & 99 & $5(5.0)$ & $2(2.0)$ & $I(1.0)$ \\
\hline Neuchatel & $|7|$ & 249 & $28(11.2)$ & $4(1.6)$ & $13(5.2)$ \\
\hline Schaffhausen & $|7|$ & 4 & $2(50.0)$ & $0(0)$ & $0(0.0)$ \\
\hline Tessin & 335 & 267 & $43(16.1)$ & $8(3.0)$ & $9(3.4)$ \\
\hline Waadtland* & 701 & 12 & $2(16.7)$ & $0(0)$ & I (8.3) \\
\hline Wallis & 308 & 103 & $6(5.8)$ & I (I.0) & $4(3.9)$ \\
\hline Total & 7776 & 3135 & 359 (II.5) & $59(1.9)$ & $|3|(4.1)$ \\
\hline
\end{tabular}

Note: *Participation was low due to another concomitant study.

Abbreviations: IFG, impaired fasting glucose; SUI-FR/IT, French/Italian-speaking part of Switzerland; SUI-GER, German speaking part of Switzerland. 
age spectrum and the variety of reasons for a pharmacy visit. One population-based study was conducted in the Frenchspeaking region of Switzerland (Lausanne), and reported an overall diabetes prevalence of $6.6 \%$ in participants aged 35-75 years, of which only $66.3 \%$ were known cases of diabetes. ${ }^{4}$ Even though the low number of study participants in the canton of Waadtland (Lausanne region) in our study does not allow for any conclusions, the overall prevalence of $6.8 \%$ in the SUI-FR/IT region (4.9\% with known $/ 1.9 \%$ with newly diagnosed diabetes) corresponds well to these published data, mostly driven by the comparatively high number of diabetic participants in the canton of Geneva (9.6\% new and known diabetes combined). Interestingly, the overall prevalence for diabetes appears to be lower in the SUI-GER part of Switzerland, especially in the cantons of Bern, Basel-Stadt, and Graubünden, but there was considerable heterogeneity observed between cantons, which remains unexplained.

\section{Diabetes and risk factor control}

The recently published Swiss health survey shows selfreported diabetes control rates of $65.5 \%$ for the year $2007 .{ }^{3}$ In line with these findings, data from our survey suggest the presence of uncontrolled diabetes in about $45 \%$ of participants with known diabetes $(29 \%$ with a diabetic profile $/ 15.3 \%$ with impaired fasting glucose) based on a single random blood glucose test and where the majority of participants were treated with oral antidiabetic drugs alone. However, these data have to be interpreted with extreme caution, given that a single capillary blood glucose test is not a suitable tool to establish the level of blood glucose control in participants with diabetes, but rather a prescreening tool. ${ }^{7}$ Further, the total number of diabetic participants was low in our study, which also represents a major limitation for making conclusions on blood glucose control in diabetic participants in Switzerland.

In our study, established cardiometabolic risk factors, such as elevated body mass index, a family history of diabetes, hypertension, hypercholesterolemia, smoking and a low level of physical exercise appeared to be associated with impaired glucose metabolism, confirming well known previous observations in this Swiss population. ${ }^{8-10}$ Even though the prognostic relevance of treating diabetes and impaired fasting glucose with regards to microvascular and macrovascular complications are undisputed, there is a lack of prospective data supporting the cost-effectiveness of structured screening initiatives. ${ }^{11-13}$ However, screening allows for early identification of individuals affected by diabetes or at risk of diabetes, and such initiatives, even when conducted at unconventional locations such as optometry practices, have been shown to be useful. ${ }^{14}$

\section{Diabetes screening}

Screening for diabetes in asymptomatic patients has been challenged recently ${ }^{15}$ for having no beneficial effect on overall health outcomes. To our knowledge, there are no randomized, controlled trial data and only one relevant casecontrol study, and neither showing a benefit when considering microvascular complications. However, there are data to support screening being effective in hypertensive persons when macrovascular benefits are considered. Therefore, targeted screening might be more effective than mass screening.

The most recent guidelines of the American Diabetes Association for screening and diagnosis of diabetes require a glycosylated hemoglobin $\geq 6.5 \%$, a fasting plasma glucose $\geq 126 \mathrm{mg} / \mathrm{dL}$ or a 2 -hour plasma glucose $\geq 200 \mathrm{mg} / \mathrm{dL}$, or symptoms of hyperglycemia in patients with a random plasma glucose $\geq 200 \mathrm{mg} / \mathrm{dL}{ }^{16}$ Fasting is defined as no caloric intake for at least 8 hours. Just as there is less than $100 \%$ concordance between fasting plasma glucose and 2-hour plasma glucose tests, there is not full concordance between glycosylated hemoglobin and either glucose-based test. Analyses of National Health and Nutrition Examination Survey data indicate that, assuming universal screening of the undiagnosed, the glycosylated hemoglobin cut point $\geq 6.5 \%$ identifies one-third fewer cases of undiagnosed diabetes than a fasting glucose cut point $\geq 126 \mathrm{mg} / \mathrm{dL}(7.0 \mathrm{mmol} / \mathrm{L}) .{ }^{16}$

In the clinical as well as in the research environment, the required fasting status is a challenging task. For clinicians and patients it is much simpler to obtain random glucose values irrespective of the fasting duration. In studies, especially epidemiologic ones, the fasting requirement influences the study design, complicates the field work, and increases the costs of the study. Moreover, and most important, it is not feasible to control reliably for self-reported fasting status. Therefore, random blood glucose values have been used as a type of prescreening measure to identify individuals in which a repeat testing under fasting conditions is necessary. ${ }^{7,17}$ For the results of the present study, this means that a number of patients (ie, those with indeterminate blood glucose) may be either normal or have impaired fasting glucose or diabetes. The conclusion is that the prevalence rates reported in our survey for new diabetes are a conservative estimate of the true prevalence. 


\section{Limitations}

Despite the straightforward approach of testing patients for the presence for dysglycemia in a large number of pharmacies in Switzerland, a number of limitations have to be considered when assessing the results of this study. A confirmation of the results of random blood glucose monitoring in largely nonfasting subjects in the same subjects after 8 hours of fasting or by assessing glycosylated hemoglobin, as suggested by the recent American Diabetes Association recommendation, would have been useful, but was not possible for logistic reasons. We obtained no data on subjects who did not participate in the study, so we cannot rule out the possibility that males, for example, who comprised $27 \%$ of the study population, were not visiting pharmacies because of having to work. Finally, the population visiting pharmacies may not be totally representative of the overall population, or may have been affected by common cold, for example, which may introduce bias into blood glucose determination.

\section{Conclusion}

In our survey, a total of 59 participants were identified with newly diagnosed diabetes by 102 pharmacies. Given that there are about 1700 retail pharmacies in Switzerland, such an initiative may contribute to identification of a substantial number of participants with unknown diabetes. This would enable early treatment and prevention of diabetes and/or diabetes-related complications.

\section{Disclosure}

The present study was conducted as a collaboration between Sanofi Aventis Switzerland and the AMAVITA pharmacy chain. At the time of this survey, AR and MT were employees of Sanofi Aventis, Switzerland. PB has received honoraria for lectures and consulting fees from a number of companies producing antidiabetic drugs, including Sanofi Aventis, Bristol Myers Squibb, AstraZeneca, and Takeda. CAM and $\mathrm{RF}$ report no conflicts of interest with respect to the current manuscript. The study was supported by Sanofi-Aventis, Meyrin, Switzerland.

\section{References}

1. Wild S, Roglic G, Green A, Sicree R, King H. Global prevalence of diabetes: estimates for the year 2000 and projections for 2030. Diabetes Care. 2004;27(5):1047-1053.

2. Herman W. The economics of diabetes prevention. Med Clin North Am. 2011;95(2):373-384.

3. Estoppey D, Paccaud F, Vollenweider P, Marques-Vidal P. Trends in self-reported prevalence and management of hypertension, hypercholesterolemia and diabetes in Swiss adults, 1997-2007. BMC Public Health. 2011;11:114.

4. Firmann M, Mayor V, Vidal PM, et al. The CoLaus study: a populationbased study to investigate the epidemiology and genetic determinants of cardiovascular risk factors and metabolic syndrome. BMC Cardiovasc Disord. 2008;8:6.

5. Schmitt-Koopmann I, Schwenkglenks M, Spinas GA, Szucs TD. Direct medical costs of type 2 diabetes and its complications in Switzerland. Eur J Public Health. 2004;14(1):3-9.

6. The International Diabetes Federation Diabetes Atlas. Available from http://www.idf.org/diabetesatlas/maps. Accessed August 29, 2012.

7. Moebus S, Gores L, Losch C, Jockel KH. Impact of time since last caloric intake on blood glucose levels. Eur J Epidemiol. 2011;26(9):719-728.

8. Knight JA. Diseases and disorders associated with excess body weight Ann Clin Lab Sci. 2011;41(2):107-121.

9. Rodriguez-Moran M, Guerrero-Romero F, Aradillas-Garcia C, et al Obesity and family history of diabetes as risk factors of impaired fasting glucose: implications for the early detection of prediabetes. Pediatr Diabetes. 2010;11(5):331-336.

10. Sanz C, Gautier JF, Hanaire H. Physical exercise for the prevention and treatment of type 2 diabetes. Diabetes Metab. 2010;36(5):346-351.

11. UK Prospective Diabetes Study (UKPDS) Group. Intensive blood-glucose control with sulphonylureas or insulin compared with conventional treatment and risk of complications in patients with type 2 diabetes (UKPDS 33). UK Prospective Diabetes Study (UKPDS) Group. Lancet. 1998;352(9131):837-853.

12. Ford ES, Zhao G, Li C. Pre-diabetes and the risk for cardiovascular disease a systematic review of the evidence. J Am Coll Cardiol. 2010;55(13): $1310-1317$.

13. Norris S, Kansagara D, Bougatsos C, Nygren P, Fu R. Screening for Type 2 diabetes mellitus: Update of 2003 systematic evidence. Review for the US. Preventive Services Task Force. Report 08-05116-EF1. Rockville (MD): Agency for Healthcare Research and Quality; 2008.

14. Howse JH, Jones S, Hungin AP. Screening for diabetes in unconventional locations: resource implications and economics of screening in optometry practices. Health Policy. 2011;102(2-3):193-199.

15. Norris SL, Kansagara D, Bougatsos C, Fu R. Screening adults for type 2 diabetes: a review of the evidence for the US Preventive Services Task Force. Ann Intern Med. 2008;148(11):855-868.

16. American Diabetes A. Diagnosis and classification of diabetes mellitus. Diabetes Care. 2012;35 Suppl 1:S64-S71.

17. Moebus S, Hanisch JU, Neuhäuser M, Aidelsburger P, Wasem J, Jöckel K-H. Assessing the metabolic syndrome according to NCEP ATP III in Germany: feasibility of a two step approach in 1550 randomly selected primary health care practices. Ger Med Sci. 2006;4:Doc7 (20061009).
Vascular Health and Risk Management

\section{Publish your work in this journal}

Vascular Health and Risk Management is an international, peerreviewed journal of therapeutics and risk management, focusing on concise rapid reporting of clinical studies on the processes involved in the maintenance of vascular health; the monitoring, prevention and treatment of vascular disease and its sequelae; and the involvement of

\section{Dovepress}

metabolic disorders, particularly diabetes. This journal is indexed on PubMed Central and MedLine. The manuscript management system is completely online and includes a very quick and fair peer-review system, which is all easy to use. Visit http://www.dovepress.com/ testimonials.php to read real quotes from published authors. 